\title{
Productivity and Superficial Quality of an Aspherical Die Using CAD/CAM
}

\author{
Gustavo Reinke ${ }^{1}$, Walter Gennari $\mathrm{Jr}^{1}$, \\ Silvio José Gobbi ${ }^{1}$
}

\footnotetext{
${ }^{1}$ Department of Mechanical Engineering, University of Brasília, 70910-900, Brasília, Distrito Federal, Brasil. e-mail: gustav.reinke@gmail.com, waltergennari1@gmail.com, silviogobbi2@gmail.com
}

\begin{abstract}
Nowadays, it is hard to imagine modern industry without the manufacturing and design software aided by computer, known as $\mathrm{CAD} / \mathrm{CAM}$, once the search for excellence in complex geometry parts, reduced time, quality assurance and interchangeability is increasing. Within this quest, the CAD/CAM platform has become a significant factor in manufacturing, especially on complex surfaces parts, mainly because of superficial quality, reliability and product competitiveness. Defined as surface within one or more non-flat surfaces or non-square, usually represented by parametric models, the freeform surfaces are very complex, requiring the control of three or more axes simultaneously, making the CAM tool indispensable. Tests were carried out by milling of aspherical cavities, on VP100 steel samples, with cemented carbide ball nose inserts with TiAlN coating. Two cutting strategies - zig-zag and spiral - and two finishing (CAM) strategies - parallel plans and Z level - were also investigated. Final Surface quality, tool productivity and tool wear were related to machining time, surface roughness (Ra, Rz, Rku and Rsk) and tool wear (VBmax). Results showed that the chosen strategy (tool path) it is the main factor to productivity.
\end{abstract}

Keywords: CAD/CAM; Superficial Quality; Milling; Finishing

\section{INTRODUCTION}

The CAD system can be defined as a computational system which aids in drawing activities, as elaboration, analysis, scaling, etc. [1]. For the CAM system, refers to manufacturing aided by a computer used to generate numeric commands programs to $\mathrm{CNC}$ machines (code $\mathrm{G}$ ), using geometric forms created by a design software [2].

Nowadays, CAD/CAM systems (Computer Aided Design/Computer Aided Manufacturing) are being used in industries, with the manufacturing problem purpose in complex geometry parts [3]. This technology was first used in the 1950's at the Massachusetts Institute of Technology (MIT). Nevertheless it had been used only by the big companies, such as the aerospace and automobilist industries, due to the high implantation costs and the need of skilled labor [4]. However, in the 1990's, this technology became more widespread with the enhancement and development of more user-friendly platforms, which made it an essential tool to the manufacturing industry [5].

Milling is a machining process in which metal is removed by a rotating multiple-tooth cutter, where each tooth removes a small amount of material with a revolution [6]. The possibility of combining this rotational movement of cutting tool with many other axis of movement, especially for machines with five or more axis, is the main reason for the large use of milling operations to machine freeform and complex surfaces. Surface roughness, which characterizes the machined part quality, is an irregularity or micro geometric error that, usually, includes the tool feed mark, built-up edge, and tool wear. According to Whitehouse [7], it can be controlled by some parameters, such as the CNC machine, the material and tool properties, cutting tool geometry and the machining process assigned.

Defined as the path to be covered by the cutting edge generating the surface, with successive trajectories and steps, the tool path exerts great importance on the surface quality and process costs. According to [8], not always the tool path, which promotes the best surface finish of the work piece, is the most recommended option due to machining cost it can add, especially in relation to the machining time which implies in greater 
productivity time. However, the recommended tool path is the one which conciliates the shorter machining time with the project specifications roughness. Still referring to the authors [8], many new tool path generation techniques have been developed in recent years to solve different problems in 5-axis machining. Some of the typical problems include how to reduce simulation and actual machining time, machining of compound surfaces and non-parametric surfaces, innovative techniques leading to decreased machining and investment cost, etc. In finishing operations, the parameters choice is not made by the maximum material removal rate, but for the smallest cutting forces, better surface quality and dimensional precision with relatively small tool wear [9]. The authors also showed that increase of machining forces cause an increase in surface roughness and also reducing the quality of surface texture. El-Midany et al. [10], reached a conclusion that the optimization of the path chosen by the tools depends on the geometry of the surface boundaries and the cutting conditions. Researchers also concluded that the optimal tool path pattern is dependent on work piece geometry, physical characteristic of used CNC machine tool (accelerator and decelerator, continuous path, look ahead, and etc.) and cutting conditions (tool diameter, feed rate, etc.).

In Figure 1, two commonly used tool path generation strategies are represented. The Figure 1a shows the spiral strategy, where the tool can move from the center to the edge or the other way around, with uniformly spaced tracks, often used to cavities machining. In Figure $1 \mathrm{~b}$ it is shown the strategy $\overline{\text {; where the tool }}$ describes parallel track with constant spacing.

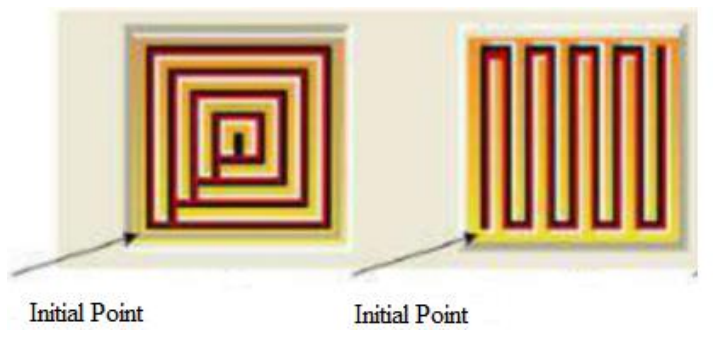

Figure 1: (a) Spiral strategy; Zig-Zag strategy [11].

The CAD systems main functions are: calculate the axis tracks, machining simulation and generation of CNC codes to specific machines [12].

The machinability of a material is determined by its structure and mechanical properties. The chip formation is, basically, influenced by the deformability, toughness and strength or metallurgical state of the part. For harder materials, due to higher demand in the contact region, there is an increase of temperature on the cutting edge and consequently greater tool wear [13]. Vibrations during the process, besides compromising the surface finish, can significantly reduce tool life in machining.

The main objective of this work is to investigate the influence of cutting strategies on tool path in milling process of an aspherical surface of a VP100 steels for molds. Tests were carried out with coated cemented carbide ball nose tools in two different grades of machining: roughing and finishing, programmed in a CAD/CAM machine. The influence of parameters, like tool path strategy and number of program lines, on productivity, surface finishing, tool wear and machining time was evaluated.

\section{METHODOLOGY AND MATERIALS}

Tests were made on a three axis ROMI CNC machine, Discovery 760 model, which consisted of milling aspherical cavities in steel blocks for dies, VP 100 - dimensions of $100 \mathrm{~mm}$ x $100 \mathrm{~mm}$ x $42 \mathrm{~mm}$, according to Figure 2a, with hardness about $300 \mathrm{HB}$. Cutting tools were cemented carbide ball nose inserts with TiAlN coating (Figure $2 b)$. 

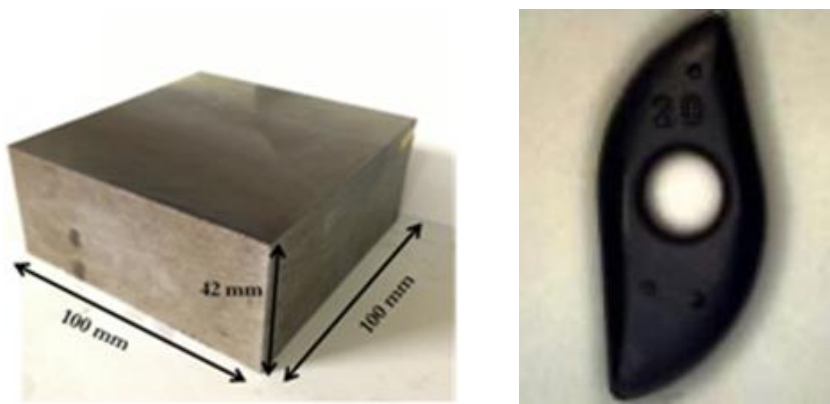

Figure 2: (a) Steel block dimensions; (b) Cemented carbide ball nose insert [14].

Four work pieces were machined in total - two with the zig-zag strategy and two with the spiral strategy. For each of those two tool path strategies, two other CAM strategies, regarding the finishing, were used - parallel plans strategy and Z level strategy, combining the following pairs:

1. zig-zag/ parallel plans;

2. zig-zag/ Z level;

3. spiral/ parallel plans;

4. spiral/ Z level.

Final surface quality, tool productivity and tool wear were related to machining time, surface roughness (Ra, Rz. Rku and Rsk) and the tool wear (VBmax). For the roughness measurements were used a interferometer Talysurf CLI 200, from Taylor Hobson, using the white light mode (CLA mode), which allows a verical resolution of $0,01 \mu \mathrm{m}$. The measurement of the top surface finish was performed considering an area of $1 \mathrm{~mm}^{2}$. In this measurement, $0,5 \mu \mathrm{m}$ between points and $2 \mu \mathrm{m}$ line spacing were used. Thus, 501 roughness profiles were collected. The sample lenghr was $0,25 \mathrm{~mm}$ and the Gauss filter was applied.

The tool wear was monitored after each test through a confocal microscope, model SZ6145TR from Olympus, with the aid of Image Pro-Express software. The wear was measure according to ISO 3685 for finishing operations.

The milling and finishing parameters are shown in Table 1 and Table 2 respectively:

Table 1: Milling parameters.

\begin{tabular}{c|c|c|c|c}
\hline \multirow{2}{*}{ Strategy } & Part 1 & Part 2 & Part 3 & Part 4 \\
\cline { 2 - 4 } & \multicolumn{2}{|c}{ Zig-zag } & \multicolumn{3}{|c}{ Spiral } \\
\hline Fz $(\mathbf{m m} /$ tooth $)$ & \multicolumn{3}{|c}{0,15} \\
\hline $\mathbf{a}_{\mathbf{p}}(\mathbf{m m})$ & \multicolumn{3}{|c}{0,4} \\
\hline Step Over & \multicolumn{3}{|c}{1,8} \\
\hline $\mathbf{v}_{\mathbf{c}}(\mathbf{m} / \mathbf{m i n})$ & \multicolumn{3}{|c}{100} \\
\hline Tolerance & \multicolumn{3}{|c}{0,1} \\
\hline
\end{tabular}

Table 2: Finishing parameters.

\begin{tabular}{c|c|c|c|c}
\hline \multirow{2}{*}{ Strategy } & Part 1 & Part 3 & Part 2 & Part 4 \\
\cline { 2 - 5 } & \multicolumn{3}{|c}{ Parallel Plans } & Z Level \\
\hline $\mathbf{v}_{\mathbf{c}}(\mathbf{m m} / \mathbf{m i n})$ & \multicolumn{4}{|c}{200} \\
\hline $\mathbf{a}_{\mathbf{p}}(\mathbf{m m})$ & \multicolumn{3}{|c}{0,2} \\
\hline $\mathbf{F z}(\mathbf{m m} /$ tooth$)$ & \multicolumn{3}{|c}{0,09} \\
\hline
\end{tabular}

Where $\mathbf{v}_{\mathbf{c}}$ is the milling speed, Fz is the tool feed rate and $\mathbf{a}_{\mathbf{p}}$ is the depth of cut. 


\section{RESULTS AND DISCUSSION}

\subsection{Work Pieces}

Figure 3 shows aspherical surfaces generated on work pieces by both finishing (CAM) strategies: Z level and parallel plans.

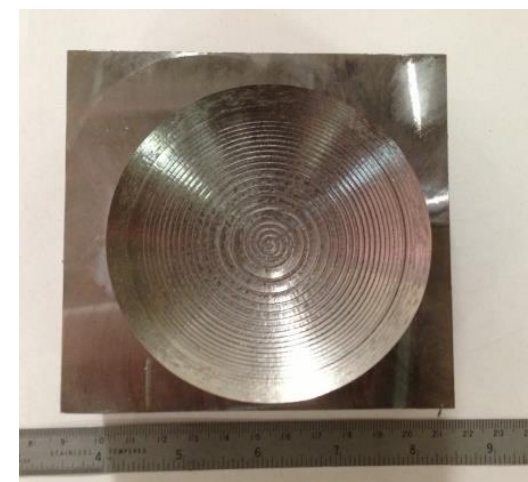

(a)

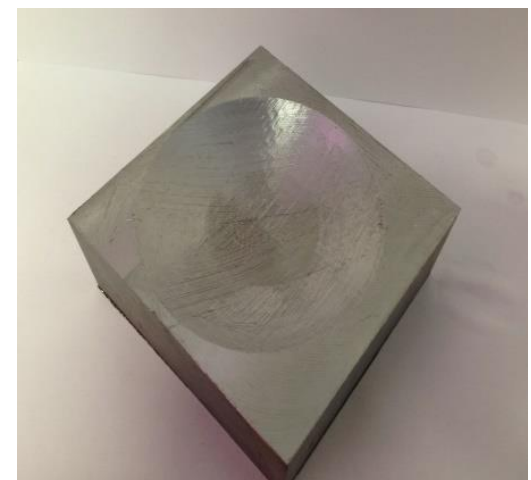

(b)

Figure 3: Finishing (CAM) strategies. (a) $\mathrm{Z}$ level; (b) Parallel plans [14].

\subsection{Roughness}

In Figure 4, it is seen that the Ra values are close to $0.60 \mu \mathrm{m}$ for both cutting strategies. The values were slight smaller for the zig-zag strategy, both for Ra and for Rz [14], typical for finish milling in molds operations.

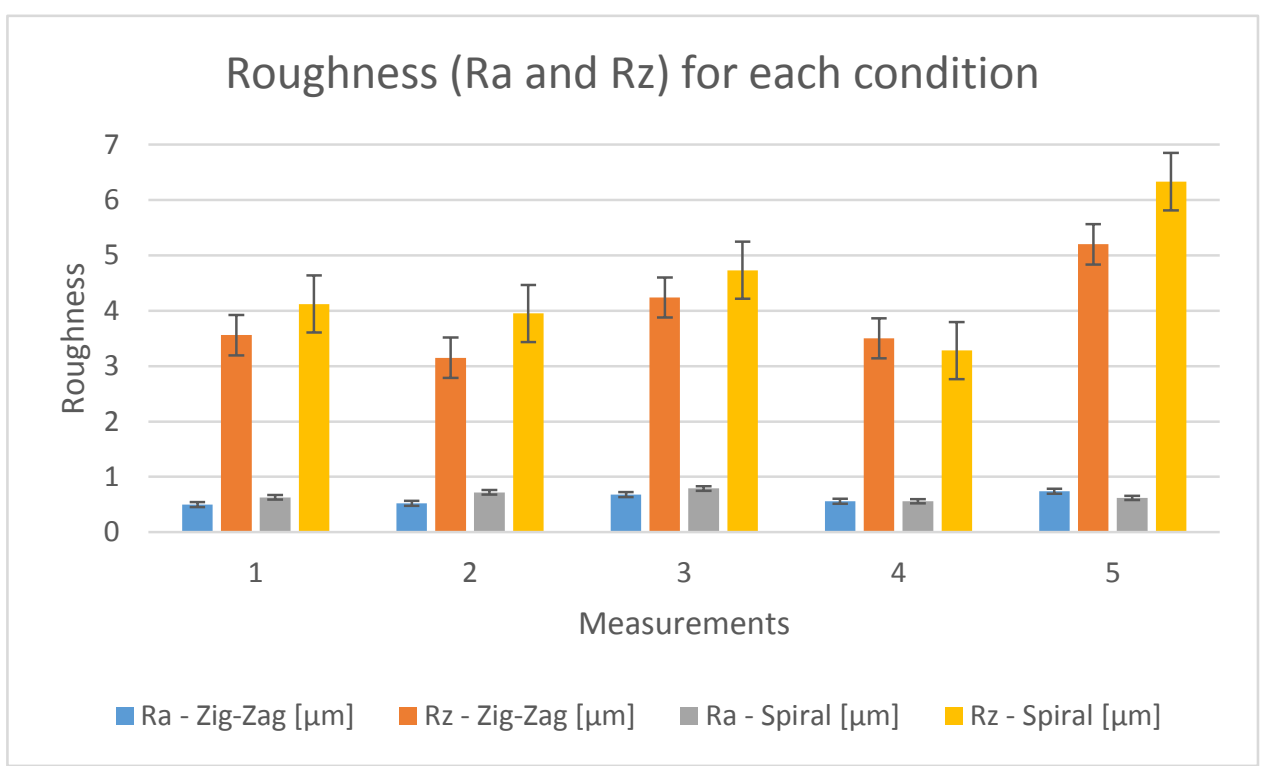

Figure 4: Roughness parameters obtained as a function of the conditions established in the milling condition.

Silva et al. [15], investigated the influence of finishing conditions on surface roughness using a ball nose tool. The authors machined a VP50 steel and verified that the roughness values remain within the range of $0,38 \mu \mathrm{m}$ and $0,72 \mu \mathrm{m}$, which is similar values found in this work. Lasemi et al. [8] suggest that surface roughness can be reduced with smaller values of step over, which was constant $(1.8 \mathrm{~mm})$ in the present research (Table 1). On the other hand, it contributes for a significant increase in machining time and a greater 
number of program lines, once the tool describes a longer path. Ramos and Machado [16], comment that when it comes to dies and molds, the requirements for injected products of better surface quality (Ra usually less than $0,1 \mu \mathrm{m}$ on the surface) have caused an increase in the difficulty of monitoring the surface finish. Besides that, polishing of complex geometries and freeform surfaces are very difficult, which requires, in many cases, finishing of work pieces by milling operations.

From Figure 5, it is seen that the average for the parameter Rku, profile flatness parameter that measures the convexity, for the spiral strategy is 5\% smaller than the zig-zag strategy; however, both have an average value greater than theoretical value 3, which implies that the surface has high peaks and lower valleys. Nevertheless, the standard deviation for the zig-zag strategy is $21 \%$ smaller, showing more distributed peaks and valleys. Leach [17], says that the Rku parameter is similar to asymmetry, and it is important for the friction analysis and lubrication retention.

Analyzing the Rsk, profile asymmetry parameter that measures the profile relative position in relation to the midline, after the milling process, zig-zag is $27 \%$ smaller when compared to the spiral strategy. Both of them show positive values, which mean a surface with high peaks associate with low valleys or flattened regions [18].

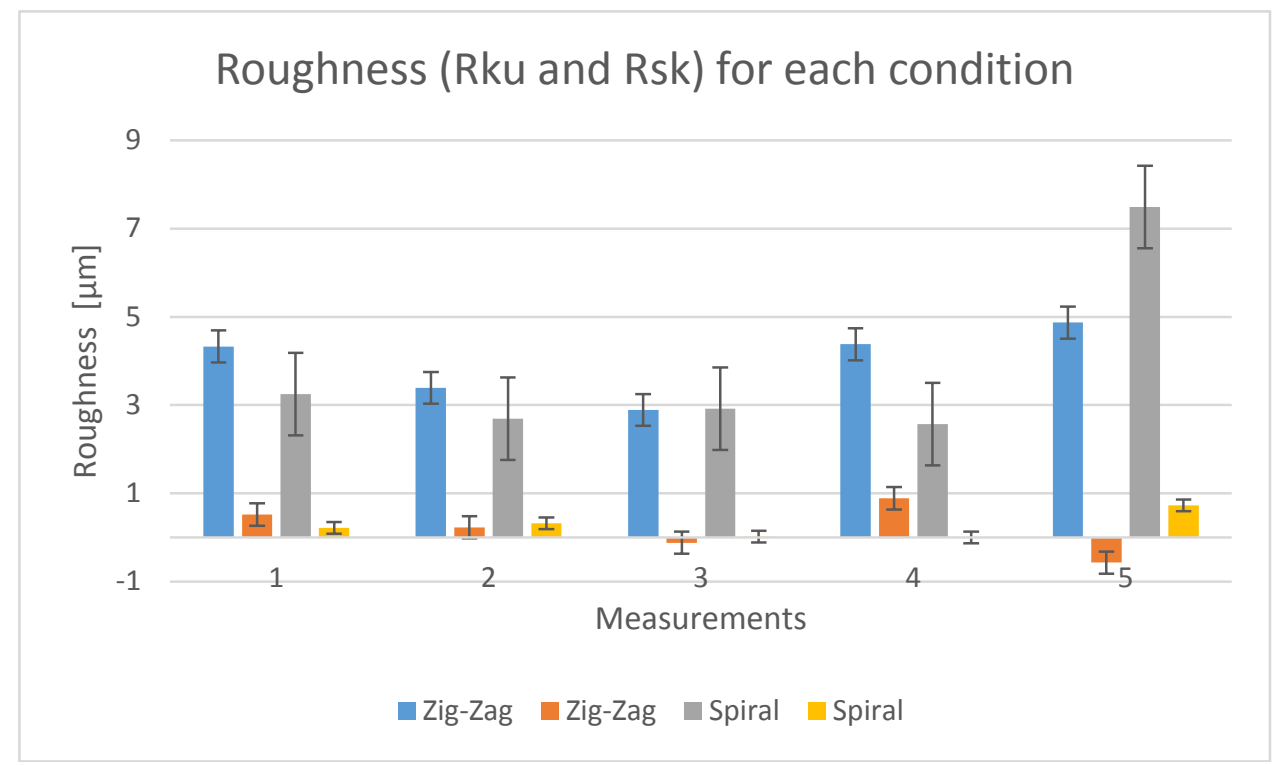

Figure 5: Roughness parameters Rku e Rsk.

\subsection{Milling and Finishing Time}

Concerning to the milling time, the results are shown in Figure 6. From the figure, it is seen that the spiral strategy time is about $24 \%$ smaller than zig-zag strategy. For the finishing, the time difference between them is very different - about 3,310 seconds. This fact can be explained based on that some strategies generate many changes of direction, which is the case for finishing strategy, parallel plans, and the zig-zag milling strategy, causing the $\mathrm{CNC}$ machine to accelerate and decelerate several times during the process, thereby leading to a substantial increase in machining time [19]. The authors also suggest that this trend is due to the combination of shorter tool paths and larger number of sharp changes in direction, as the angle for zig-zag tool path orientation angle increases. With shorter tool paths there is less time for the machine to accelerate to the programmed feed rate. 


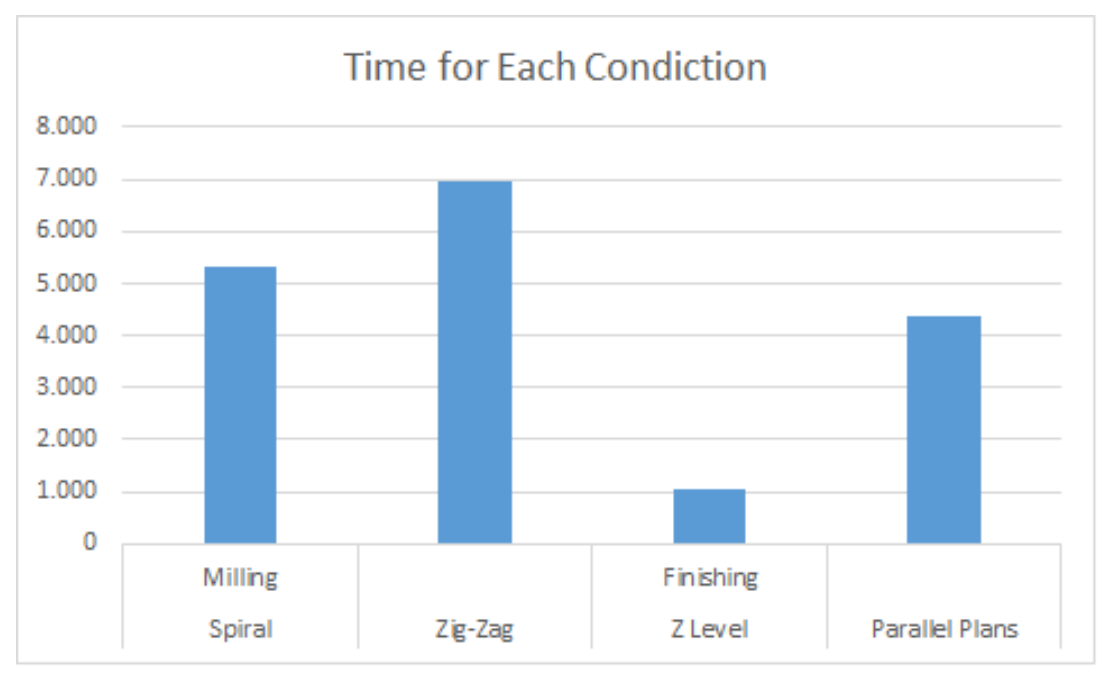

Figure 6: Time for each condition

\subsection{CNC Program}

When the number of program lines is analyzed, for each condition, the spiral strategy it is around 58\% smaller than the zig-zag strategy. When the finishing strategies are compared to each other, it is visible that the parallel plans strategy has more program lines than the $\mathrm{z}$ level strategy. From the literature is known that the strategy that makes more use of linear interpolation, e.g. zig-zag and parallel plans, will contain a greater number of segments and consequently a greater number of program lines. According to Arias [20], when machining the same geometry, there is a connection between the size of a generated program and the machining time, which tends to be larger as the number of program lines increases. In addition, the author observed that each CAM system generates programs with different sizes, depending on the number of calculated points used to produce the work piece within the required geometry. The values for each condition are shown in Table 3.

Table 3: Program lines and size of the program on each condition.

\begin{tabular}{c|c|c|c}
\hline Condition & Strategy & Program lines & Program size (kb) \\
\hline \multirow{2}{*}{ Milling } & Spiral & 2.666 & 124 \\
\cline { 2 - 4 } & Zig-zag & 6.329 & 149 \\
\hline \multirow{2}{*}{ Finishing } & Z Level & 7.646 & 166 \\
\cline { 2 - 4 } & Parallel Plans & 12.539 & 262 \\
\hline
\end{tabular}

\subsection{Tool Wear}

After milling and finishing steps, the tool wear was measured with an confocal optical microscopy. The measurement was performed at the tool tip. Figure 7 shows the measured wear values after the milling process. 


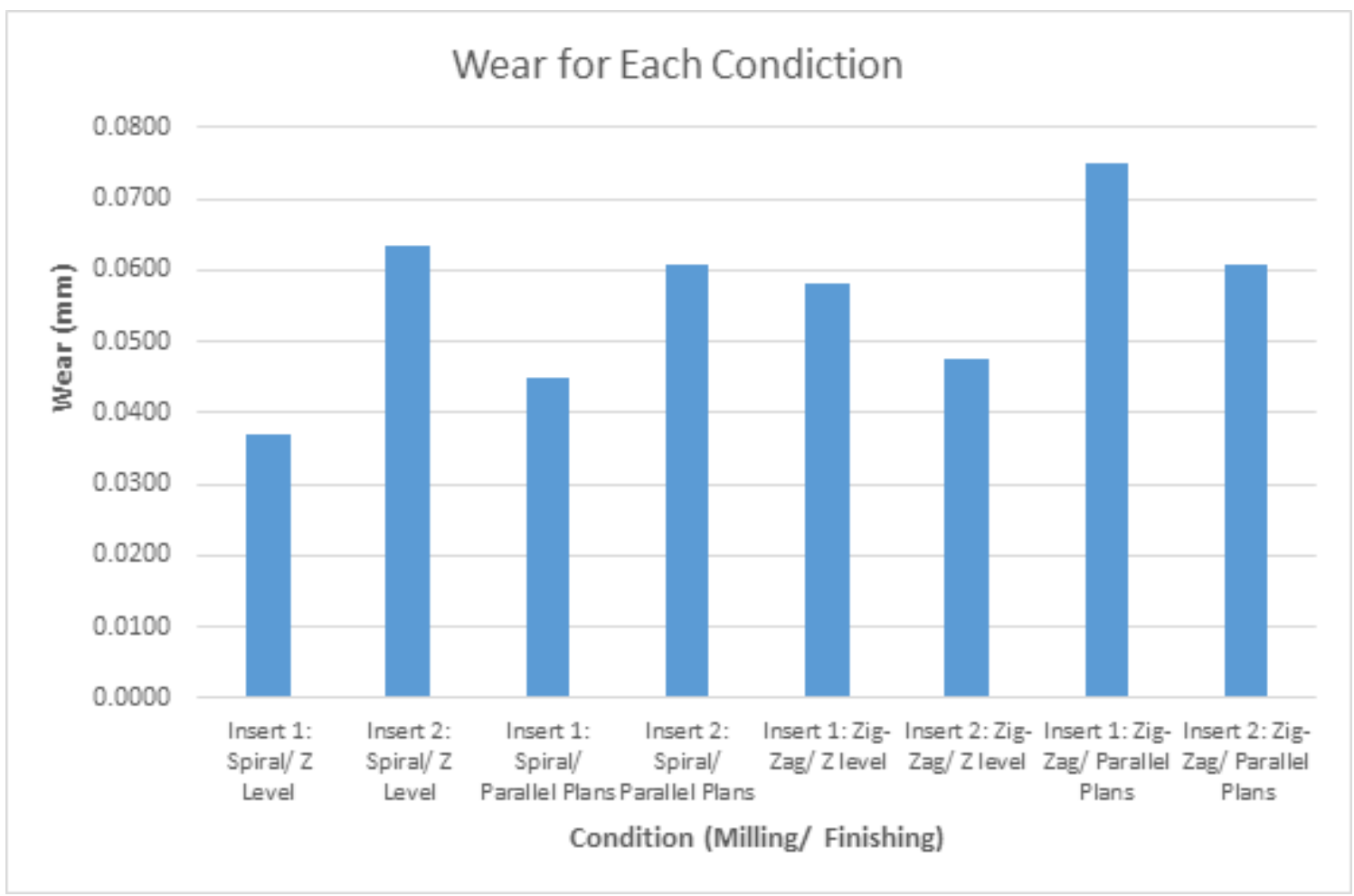

Figure 7: Wear values from the inserts on each condition.

In Figure 8, it is shown the tool wear for four conditions pairs. As it can be seen, the wear values were very small; however, the values for the pair zig-zag/ parallel plans are slightly bigger when compared with the values for the others pairs. Knowing that such finishing condition, parallel plans, presented a larger number of program lines and also a longer machining time indicating that the tool remained a longer period of time in contact with the work piece and, consequently, higher wear would be expected. Regarding to the tool wear, in general the values, highest and lowest, were not so disparate, suggesting that for all tests the tools kept wear in phase I - where the effective contact area between surfaces is much smaller than the apparent area, leading to a relatively low tool wear rate and a good integrity of cutting edge, e.g. [21].

In Figure 9, it is shown a bar chart, which makes a relation between the machined time for each pair of conditions and the tool wear. As it can be seen, the tool wear has not changed a lot, since the machining time is quite different for each pair of condition, with a difference of a 4.949 seconds between the pair spiral/ z level and the pair zig-zag/ parallel plans.

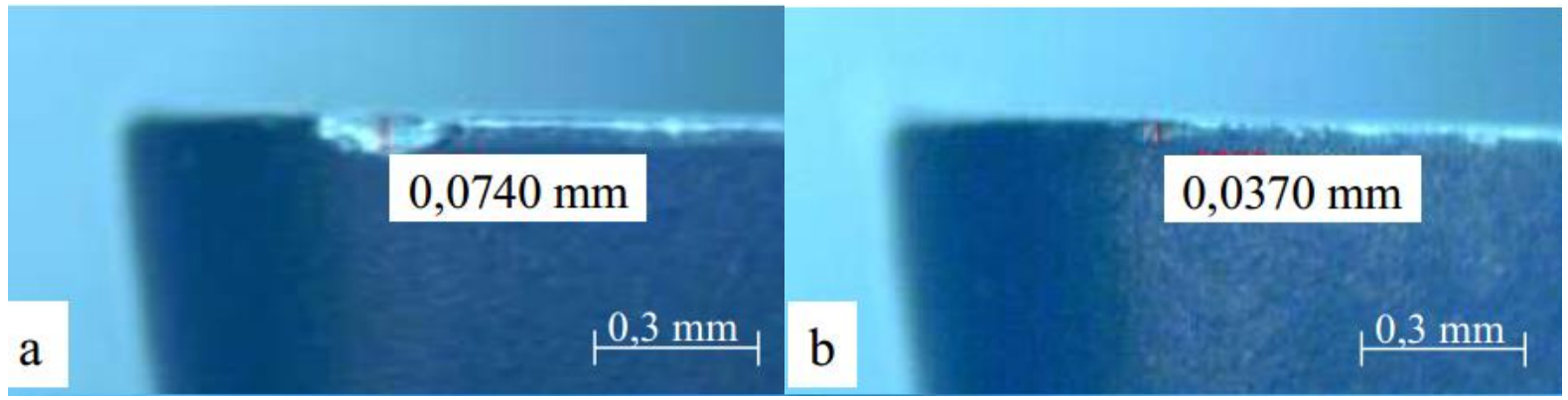




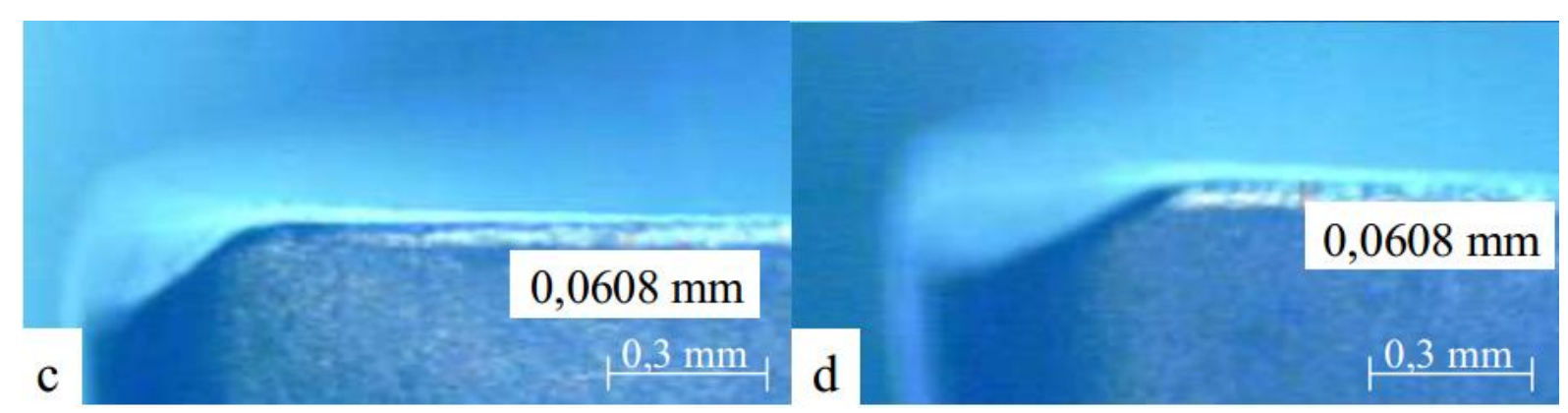

Figure 8: Tool Wear. (a) Zig-zag/ Parallel Plans; (b) Spiral/ Z level; (c) Spiral/ Z level; (d) Zig-zag/ Parallel Plans.

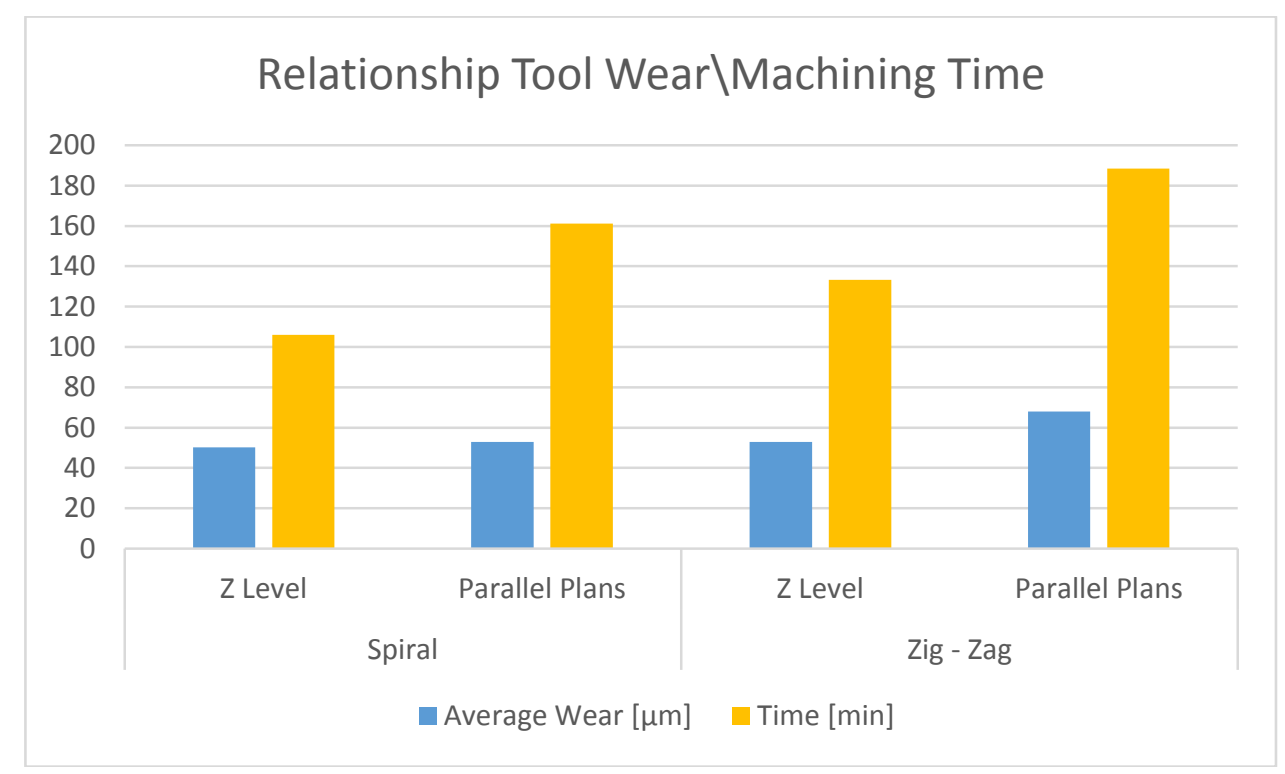

Figure 9: Relationship between tool wear and machined time. 


\section{CONCLUSION}

Regarding to the free form surfaces milling, there is too much to explore due the vast application field. The correct selection of the cutting tool, cutting parameters and knowledge of tool path for a given material and certain geometry can lead to a reduction in manufacturing costs and machining times.

Thus, from the analysis of these results, the following conclusions can be drawn:

1. Despite the great difference of productivity between investigated strategies, surface roughness values didn't show significant differences for each of them.

2. Despite the large productivity difference between each strategy (tool path) - ranging 6.361 seconds to 11.310 seconds - the tool wear values varied very little (from $0,0502 \mathrm{~mm}$ to $0,0679 \mathrm{~mm}$ ). It means that the chosen strategy (tool path) it is the main factor to productivity.

3. The selected milling strategy influenced the roughness and the zig-zag strategy allowed roughness values slightly lower than the spiral strategy, suggesting that the milling exerts influence on the final roughness, but that influence was not as big as difference of productivity for each strategy.

4. Although dependent on the strategy, the machining time and program lines do not change proportionally.

\section{BIBLIOGRAPHY}

[1] WELter JR., A., HOUNSELl, M. S., "O (Mau) Uso das Ferramentas CAD, CAM e CAE”, In: $X X$ Congresso e Exposição Internacionais de Tecnologia da Mobilidade, v. 1, n. 1, pp. 3503, 2002.

[2] FIGUEIRA, R. J. C. M., “CAD/ CAE/ CAM/ CIM, "Licenciatura em Computadores e Sistemas, Instituto Tecnológico do Porto, Portugal, 2003.

[3] COSTA, D. D., VOLPATO, N., "Usinagem de Formas Complexas Empregando a Técnica de Fatiamento", In: $4^{\circ}$ Brazilian Congress Brasileiro of Manufacturing Engineering, Brazil, 2007.

[4] SOUZA, A. F., COELHO, R. T. “Tecnologia CAD/CAM - Definições e estado da arte visando auxiliar sua implantação em um ambiente fabril”, In: XXIII Encontro Nacional de Engenharia de Produção. Brazil, 2003.

[5] HELLENO, A. L., SCHÜTZER, K., "Fatores que Influenciam a Usinagem de Moldes e Matrizes com Altas Velocidades", Revista Ciência \& Tecnologia, v.12, n²3, pp. 7-14, Brazil, 2004.

[6] AMERICAN SOCIETY OF MATERIALS, ASM Metals Handbook: Machining, vol. 16, Ohio, USA: ASM International, 1995.

[7] WHITEHOUSE, D. J. Handbook of Surface and Nanometrology, Ed. Bristol: Institute of Physics, pp. 8$13,2003$.

[8] LASEMI, A., XUE, D., GU, P., "Recent Development in CNC Machining of Freeform Surfaces: A Stateof-Art Review," Computer Aided Design, (42), pp.641-654, 2010.

[9] THO, C. K. "Study of the Effects of Cutter Path Strategies and Orientation in Milling," Journal of Materials Processing Technology, 152, 2004.

[10] EL-MIDANY, T. T., ELKERAN, A., TAWFIK, H., “Toolpath Pattern Comparison: Contour-Parallel with Direction-Parallel," Geometric Modeling and Imaging, pp. 77-82, 2006.

[11] RODRIGUES, M.A, "Desgaste das Ferramentasde Corte e Acabamento Superficial a Partir de Diferentes Estratégias CAD/CAM," Revista Máquinas e Metais, Aranda Ed., n. 516, pp. 112-141, 2009.

[12] SOUZA, A. F., ULBRICH, C. B. L., Engenharia Integrada por Computador e Sistemas CAD/ CAM/ CNC: Princípios e Aplicações, Ed. Artliber, Brazil, 2009.

[13] SCHULZ, H., High-Speed Machining, München: Carl Verlag, pp. 286, 1996.

[14] REINKE, G., Fresamento de um Molde para Lente Asférica com Diferentes Estratégias com o Auxílio do Software CAD/CAM, BSc Thesis. Federal University of Uberlândia, Uberlândia, MG, 2013.

[15] SILVA, R. B., COSTA, G. G. S., DUARTE, R. F., "Influências e Condições de Corte no Acabamento e Tempo de Usinagem Durante o Fresamento em Aço Endurecido com Fresa Ball Nose", In: 6th Brazilian Congress Manufacturing Engineering. Brazil, 2011.

[16] RAMOS, C. A. D., MACHADO, A. R., “Usinagem de Moldes e Matrizes”, In: 8th Colóquio de Usinagem, PUC-MG, Brazil, 2002. 
[17] LEACH, R., Measurement Good Practice Guide $n^{\circ}$ 37: The Measurement of Surface Texture Using Stylus Instrument, UK, 2001.

[18] MACHADO, A., Avaliação da Rugosidade em Superfícies Complexas, MSc Thesis, Instituto Superior Tupy. Joinville, SC, Brazil, 2009.

[19] MONREAL, M., RODRIGUEZ, C.A., "Influence of Tool Path Strategy on the Cycle Time of HighSpeed Milling”, Computer Aided-Design, v.35, n. 4, pp. 395-401, London, UK, 2003.

[20] ARIAS, M. L., Análise do Comportamento de Diferentes Sistemas CAM na Usinagem de Superfícies Complexas Utilizando Altas Velocidades, MSc Thesis, Joinville, SC, Brazil, 2009.

[21] MACHADO, A.R., COELHO, R.T., ABRÃO, A.M., SILVA, M.B., Teoria da Usinagem dos Metais, Ed. Blucher, pp. 384, 2009.

\section{ORCID}

Gustavo Reinke http://orcid.org/0000-0001-7457-0864

Walter Gennari Jr. http://orcid.org/0000-0001-5529-7823

Silvio José Gobbi http://orcid.org/0000-0002-7310-1422 